Revista lus et Praxis, Año 16, N² 2, 2010, pp. 393 - 414

ISSN 0717 - 2877

Universidad de Talca - Facultad de Ciencias Jurídicas y Sociales

"Prisión preventiva, terremoto y saqueos:

Comentario a las sentencias de la Corte Suprema"

Humberto Alarcón Corsi

\title{
PRISIÓN PREVENTIVA, TERREMOTO Y SAQUEOS: COMENTARIO A LAS SENTENCIAS DE LA CORTE SUPREMA*
}

Humberto Alarcón Corsi**

\section{Contexto de LAS SENTENCIAS COMENTADAS}

Momentos después del terremoto y maremoto del 27 de febrero de 2010, ocurrido en la zona centro sur del país, se produjeron sucesos consistentes en ataques masivos a establecimientos de comercio, los cuales fueron calificados de saqueos ${ }^{1}$. Dichos hechos ocurrieron especialmente en los principales centros urbanos de la Provincia de Concepción, capital de la Región del Bío-Bío, los que produjeron preocupación y temor en la ciudadanía². La autoridad de la época ${ }^{3}$, dados los sucesos descritos, decretó de conformidad con lo dispuesto en el artículo 40 No 2 de la Constitución Política de la República (en adelante CPR), el estado excepcional de emergencia constitucional, con la finalidad de: 1) Mantener, y garantizar el orden público en las regiones más afectadas por el terremoto y maremoto; 2) Permitir que la ayuda estatal Ilegase a las víctimas,

\footnotetext{
* Colaboración recibida el 20 de octubre y aprobada el 29 de octubre de 2010.

** Abogado, Universidad de Talca; Mg. Derecho Penal. Profesor de Derecho Penal, Universidad de Talca; Defensor Local Jefe de Concepción. Correo electrónico: halarcon@utalca.cl.

${ }^{1}$ Dicha expresión no existe, al menos como una categoría típica en el texto de nuestro Código Penal, ni en nuestra legislación. Sin embargo, fue utilizada masivamente por toda la comunidad a partir del 27 de febrero de 2010. Así puede verse en los titulares de los periódicos de aquellos días, a modo ejemplar: véase portada de los diarios: "La Tercera" del 1 de marzo de 2010. En: http://papeldigital.info/lt/index. html?2010030101 [visitado el: 17/10/2010] y cuerpo de reportajes del diario "El Sur" de Concepción, de fecha 21 de marzo de 2010. En: http://www.elsur.cl/diarioelsur/20100321/16/papeldigital.html [visitado 17/10/2010]. A diferencia de lo que ocurre en las ciencias jurídicas, en otras ciencias sociales, la conceptualización de los saqueos ha tenido un mayor desarrollo, así Green, Stuar, "Looting, Law, and Lawlessness", 2006, p. 7, En: http://law.bepress.com/cgi/viewcontent.cgi?article=6879\&context=expr esso [visitado el 21/09/2010], conceptualiza los saqueos, "como entrar sin autorización a una casa o negocio el cual no posee sistemas de seguridad en virtud de la vulnerabilidad producida por un desastre natural o desórdenes colectivos, obteniendo así el control, y removiendo o dañando la propiedad de otros sujetos" Indica, que el origen histórico de dicho concepto se vincula con la guerra.

2 Para una cabal comprensión de la situación, puede consultarse en la Web cualquier periódico de circulación nacional o regional.

${ }^{3}$ Con fecha 28 de febrero de 2010, la ex Presidenta de la República, Sra. Michelle Bachelet, decretó el estado de excepción constitucional de emergencia.
} 
y 3) Finalmente, entre otras, permitir la iniciación de las labores de reposición y/o reconstrucción de los servicios básicos que habían sido dañados por el evento natural ya referido. Días más tarde, la policía bajo la dirección del Ministerio Público realizó operativos policiales que condujeron a la detención de un número importante de ciudadanos (los Ilamados saqueadores). La gran mayoría de ellos, o casi su totalidad, eran quienes poseían, guardaban o tenían a cualquier título, especies muebles que provenían de dichos actos; es decir, autores del delito de receptación, tipificado y sancionado en el artículo 456 bis A del Código Penal (en adelante CP). Todas estas personas fueron formalizadas por este delito, y en su minoría por el delito de robo con fuerza en las cosas que se encuentran en lugar no habitado, tipificado y sancionado en el artículo 442 del CP. En casi la totalidad de los $\operatorname{casos}^{4}$, se decretó la prisión preventiva de los imputados formalizados, pues los magistrados que conocieron de dichos causas, consideraron que la libertad de estas personas constituía un "peligro para la seguridad de la sociedad". Sin duda, que hasta aquí no hemos dicho nada nuevo, pues dichas acciones -las detenciones y posteriores privaciones de libertad- podrían ser consideradas como una consecuencia esperada, y por algunos necesaria, ante los sucesos que hemos narrado; pero sin duda, ello sólo puede ser pacífico, en tanto y en cuanto, dicho discurso sea analizado desde una sola mirada: "La gravedad de los hechos ocurridos en una catástrofe natural". Más aún, puede ser la consecuencia de la actual configuración de ciertos agentes sociales capaces de generar visiones y/o puntos de vista en el actual esquema social, como son los medios de comunicación. Sin embargo, dicho análisis pasa a ser cuestionable, cuando se comienza a revisar cada caso, conforme con la regulación legal de la prisión preventiva y con la naturaleza misma de dicha institución.

En este sentido, el presente comentario analiza dos resoluciones de la Excelentísima Corte Suprema, referentes a delitos de receptación ocurridos horas después del terremoto y maremoto del 27 de febrero. Se revisará la procedencia y finalidad de la prisión preventiva en un estado de excepción constitucional, para terminar concluyendo que la imposición de esta medida cautelar, aun en un

\footnotetext{
${ }^{4}$ Según información del Sistema Informático de Apoyo a la Gestión de Defensa Penal Pública (SIGDP), al 17 de junio de 2010, en la Región del Bío-Bío, hubo 324 personas en prisión preventiva por hechos vinculados a los sucesos post 27 de febrero de 2010. De esta cifra, 166 personas habían sido formalizadas por el delito de receptación; otras 14, por el delito de hurto simple; 66 por el delito de robo con fuerza de cosas que se encuentran en un lugar habitado o destinado a la habitación, y 78 personas formalizadas y sometidas a prisión preventiva por el delito de robo con fuerza en las cosas que se encuentran en un lugar no habitado. Esta información fue proporcionada por el encargado de la Oficina de Información, Reclamación y Sugerencias (OIRS) de la Defensoría Regional del Bío-Bío, Sr. Pablo Carrasco Pérez, mediante correo electrónico de fecha 22 de septiembre de 2010. Como se ve, no existió ninguna ponderación para decretar la prisión u otra medida cautelar, en uno u otro delito, tal como se insistirá más adelante.
} 
estado excepcional de garantías, como el vigente a la época de los hechos por los cuales se impuso, no cumplió más que con fines puramente simbólicos.

\section{Consideraciones y fundamentaciones de las Sentencias de la Excelentísima Corte Suprema, Rol No 2218-2010 y Rol No 1975-2010}

a) Dada la similitud de los hechos y las fundamentaciones de las resoluciones, se describirán en forma conjunta las sentencias que serán objeto del presente comentario. Así, en ambos casos se trata de imputados que fueron formalizados por delitos de receptación ${ }^{5}$, esencialmente por guardar en su domicilio una serie de alimentos no perecibles en un caso; y en el otro una lavadora. Ambos imputados gozaban de irreprochable conducta anterior, no teniendo ni siquiera antecedentes policiales previos, es decir, se trataba de su primer contacto con el sistema criminal. Las resoluciones que decretaron la prisión preventiva tuvieron por acreditado el presupuesto material, es decir, se acreditó la existencia del delito y la participación, pese a que en uno de los casos al menos, ni siquiera en los hechos formalizados se indicaba a quién pertenecía el artefacto electrodoméstico que se imputada haber tenido en su poder, simplemente, se indicaba que provenía de bodegas comerciales de la ciudad, sin saber a cuál de todas las casas comerciales que tienen bodegas en dicho lugar pertenecía ese objeto. Se consideró, además, que la libertad de los imputados era peligrosa para la seguridad de la sociedad. Dicho peligro habría estado dado por lo siguiente: 1) El Ministerio Público invocó las agravantes contenidas en: a) El artículo 12 № 10 del Código Penal, y b) la agravante contenida en el inciso $7^{\circ}$ del artículo $5^{\circ}$, de la Ley $\mathrm{N}^{\mathrm{0}} 16.282^{6}$; 2) El estado de excepción que estaba vigente en la ciudad; 3) El carácter y ocurrencia del hecho punible y su impacto en la mantención

\footnotetext{
${ }^{5}$ En la causa RUC 1010006270-K, los hechos que constan en el acta de formalización son: "El día 16 de marzo de 2010, siendo la 11:20 horas de la mañana aproximadamente, el imputado M.A.M.Z tenía en su poder al interior de su domicilio ubicado en ..., comuna de Concepción, distintas especies de propiedad del supermercado Alvi, a saber, 3 cajas de cereal Nestum, 8 paquetes de corbatas marca Aconcagua, un paquete de espirales marca Carozzi, 8 cajas de café marca Nescafé contenedoras de 100 sobres cada una, dos caja de café marca Gold contenedoras de 100 sobres cada una y 30 cajas de Té Club etiqueta roja. Dichas especies habían sido robadas desde el supermercado Alvi, ubicado en Avenida Los Carrera No 555 de la comuna de Concepción el día 28 de febrero de 2010 producto de los saqueos que afectaron a distintos locales de Concepción en forma posterior al terremoto de fecha 27 de febrero de 2010; el imputado sabía o no podía menos que saber el origen ilícito de dichas especies".

En la causa RUC 010005682-3, los hechos son: "El día 7 de marzo de 2010, alrededor de las 00:30 horas de la madrugada, el imputado Carlos Rubén J. S., mantenía en su poder una lavadora marca Cónsul, la cual había sido sustraída desde el interior de las bodegas de tiendas comerciales ubicadas en el sector Palomares de la comuna de Concepción. El imputado conocía, o no podía menos que conocer el origen ilícito de las especies".

${ }^{6}$ El artículo $5^{\circ}$ inciso $7^{\circ}$, dispone: En los delitos contra las personas o la propiedad será considerado agravante el hecho de haber sido cometido el delito en la zona afectada.
} 
del orden público, alterado ostensiblemente por los desmanes, robos y hurtos por saqueadores.

Frente a dichas resoluciones, los defensores penales públicos de los imputados, presentaron ante la Ilustrísima Corte de Apelaciones de esa misma ciudad la acción constitucional de amparo, fundándola, esencialmente en: 1) La falta del presupuesto material de la medida cautelar decretada y 2) La falta de proporcionalidad de la misma medida.

b) La Ilustrísima Corte de Apelaciones de Concepción rechazó las acciones constitucionales de amparo, indicando esencialmente y escuetamente, tanto en la resolución de fecha 12 de marzo de 2010, como la del 22 del mismo mes y año, que la resoluciones del Juzgado de Garantía de Concepción, que habían decretado la prisión preventiva en contra de los recurridos, fueron expedidas conforme a derecho, observado el cumplimiento de los requisitos del artículo 140 del Código Procesal Penal (en adelante CPP). Es decir, la Ilustrísima Corte de Apelaciones no se pronunció mayormente sobre la falta de presupuesto material, ni sobre la falta de proporcionalidad de la medida cautelar.

c) La defensa de los amparados apeló las resoluciones antes indicadas. Así, estos hechos fueron de conocimiento de la Excelentísima Corte Suprema, la cual, en ambos casos, confirmó lo resuelto por la Ilustrísima Corte de Apelaciones de Concepción, sin mayor fundamentación, con la única salvedad de que, en uno de los casos -sentencia Rol 2218-210- fue confirmada, por mayoría, con un voto en contra, el cual estuvo por acoger la acción constitucional de amparo, en virtud del carácter de ultima ratio de la medida cautelar.

Conviene aclarar que las resoluciones que se analizarán tratan de casos en que: 1) El delito imputado no es de aquellos cuya gravedad amerita, en todo caso y en abstracto, la exclusión de beneficios alternativos al cumplimiento de la pena en forma privativa de libertad, 2) Se trata de imputados con irreprochable conducta anterior, lo que implica que en el peor de los casos, si éstos llegasen a ser condenados, no cumplirían sus penas en forma efectiva, 3) En uno de los casos, al menos, se trata de hechos que aisladamente considerados, pueden ser calificados como insignificantes o de bagatela ${ }^{8}$ y 4) Se trata de resoluciones,

\footnotetext{
${ }^{7}$ Nos referimos a las resoluciones de la llustrísima Corte de Apelaciones de 22 de marzo de 2010, Rol 6-2010. En: http://corte.poderjudicial.cl/SITCORTEPORWEB/?opc_menu=7 [visitado el 21/09/2010]; y resolución de la Iltma. Corte de Apelaciones de Concepción, que rechazó acción constitucional de amparo, de fecha 12 de marzo de 2010, Rol 1-2010.

${ }^{8}$ Al respecto, Silva SÁnchez, Jesús María, "Delincuencia patrimonial leve: una observación del estado de la cuestión", Revista de Estudios Penales y Criminológicos No 25, Universidad de Santiago de Compostela, 2005, pp. 333-334, para quien: "Los delitos patrimoniales leves muestran características específicas en el conjunto de la criminalidad. Por un lado, aisladamente considerados, muestran una lesividad muy limitada -se consideran, en general, hechos de bagatela-, de modo que la imposición de sanciones penales convencionales podría parecer escasamente justificada desde la perspectiva del
} 
que no cumplen la exigencia de fundamentación contenida en los artículos 36 y 143 del Código Procesal Penal.

\section{RESPECTO A LA MEDIDA CAUTELAR DE PRISIÓN PREVENTIVA}

\section{Consideraciones generales}

La doctrina procesal penal tradicional atribuye a la prisión preventiva una misión puramente cautelar o provisional, lo que se encuentra dado esencialmente, por cuanto a través de ella se pretende el aseguramiento de la realización de los actos del procedimiento, lo que implica el juzgamiento efectivo del acusado y la ejecución de la sentencia del presunto responsable cuando sea el caso $^{9}$, lo que podría verse frustrado, por cuanto el imputado podría darse a la fuga, lo que imposibilitaría la realización del juicios y la imposición de la

principio de proporcionalidad. Por otro lado, sin embargo, también es cierto que afectan a un derecho individual que resulta esencial en la autocompresión de nuestra sociedad (la propiedad privada). En tercer lugar, expresan una forma de comportamiento típica de la sociedad de masas, esto es, conforman a su vez un fenómeno masivo. Ello determina que den lugar a daños materiales globales muy elevados, que incidan de modo directo en la sensación social de inseguridad y que, a la vez, contribuyan de modo decisivo a la sobrecarga de la administración de justicia penal pese a la elevada cifra oscura existente también en este ámbito".

${ }^{9}$ Duce Julio, Mauricio; Riego R., Cristián, Proceso Penal, Editorial Jurídica de Chile, Santiago, 2007, p. 250, para quienes la prisión preventiva, conforme la regulación del artículo $4^{\circ}$ del Código Procesal Penal, que establece el principio de inocencia, "podría resultar justificable que para poder llevar adelante el proceso, y para asegurar el cumplimiento de la decisión que se tome en la sentencia, adoptar medidas de resguardo que signifiquen formas de coerción intensas sobre el imputado", con lo que reconocen el carácter cautelar de la prisión preventiva como medida cautelar personal. CAROCCA Pérez, Álex, Manual El Nuevo Sistema Procesal Penal, Editorial LexisNexis, Santiago, 2005, p. 156, para quien las medidas cautelares, entre ellas la prisión preventiva, sólo tienen como finalidad la realización de los fines de procedimiento, y por ello su temporabilidad, es decir, duran mientras éstos subsistan. En una opinión similar, pero con una variante importante se encuentran: HoRvitz LENNON, María Inés; López MAsLe, Julián, Derecho Procesal Penal Chileno, Tomo I, Editorial Jurídica de Chile, Santiago, 2002, p. 344, para quienes si bien las medidas cautelares personales, entre las cuales está la prisión preventiva, están llamadas a "asegurar la persona del imputado en el curso del procedimiento penal" -naturaleza cautelar propiamente tal- reconocen estos autores que existen las denominadas "medidas de coerción procesal" que "exceden la naturaleza cautelar que supone la tutela de fines procesales", citando a modo de ejemplo la prisión preventiva cuando es impuesta como medida de peligrosidad social, para tal efecto, critican duramente la causal de peligro para la seguridad de la sociedad, como una justificación de naturaleza cautelar para imponer una privación de libertad. En el derecho comparado, Roxin, Claus, Derecho Procesal Penal, Traducción de Córdoba, Gabriela; Pastor, Daniel, Revisada por Mayer, Julio, Editores del Puerto, Buenos Aires, 2000, p. 257. Para quien la prisión preventiva en el proceso penal es la privación de la libertad del imputado con el fin de asegurar el proceso de conocimiento o la ejecución de la pena. Ella sirve a tres objetivos: 1 . Pretende asegurar la presencia del imputado en el procedimiento penal (\$112, II, $\mathrm{N}^{\circ}$ s. 1 y 2). 2. Pretende garantizar una investigación de los hechos, en debida forma, por los órganos de la persecución penal (\$112, II, № 3). 3. Pretende asegurar la ejecución penal (§ 457). 
condena; y/o la destrucción de las pruebas de cargo, lo que imposibilitaría a la acusación probar la culpabilidad del acusado, con lo cual también se frustraría la imposición de la pena.

En nuestra legislación, la prisión preventiva se encuentra regulada a nivel constitucional, en el artículo $19 \mathrm{~N}^{\circ} 7$ letra e) y en el artículo $5^{\circ}$ inciso $2^{\circ}$, de la $\mathrm{CPR}$, que introduce a la legislación interna los tratados internacionales sobre derechos fundamentales. Por otro lado, el propio CP, regula dentro de su Libro I, Título V, las medidas cautelares personales, y en el párrafo $4^{\circ}$ la prisión preventiva, regulación que en términos generales exige que ésta sea decretada por resolución judicial fundada (artículo 143 del CPP), en una audiencia pública, una vez que el Ministerio Público o el querellante, en su caso, puedan acreditar, con antecedentes fundados, la existencia del delito. Además, se les exige que esos mismos antecedentes permitan presumir fundadamente la participación del imputado en dicho hecho típico y antijurídico (artículo 140 letras a) y b) del CPP). Además de dicho presupuesto, al que comúnmente se le suele llamar materia ${ }^{10}$, se exige según lo entiende la doctrina y la jurisprudencia, el llamado presupuesto cautelar. En este sentido, no es baladí que el legislador, al momento de comenzar la regulación de esta medida, resalte dicho presupuesto, al indicar en el artículo 139 del CPP, que: "La prisión preventiva procederá sólo cuando las demás medidas cautelares personales fueren estimadas por el juez como insuficientes para asegurar las finalidades del procedimiento, la seguridad del ofendido o de la sociedad". Así, el artículo 140 del CPP en su letra c), distingue cuatro causales alternativas, que configuran la necesidad de cautela, y que justifican la prisión preventiva de una persona que se presume inocente. Estas causales son señaladas por el legislador mediante cláusulas genéricas que, a su vez, en algunos casos añaden cláusulas específicas pensadas para casos especiales como: reiteración o habitualidad en conductas delictivas. Estas causales son: 1) Peligro para la seguridad del ofendido, 2) Peligro para el éxito de diligencias precisas y determinadas de la investigación, 3) Peligro para la seguridad de la sociedad, y 4) Peligro de fuga ${ }^{11}$. Así entonces, la necesidad de cautela en nuestra

\footnotetext{
${ }^{10}$ Entre otros, Duce; Riego, Proceso, cit., nota n. 9, p. 251.

${ }^{11}$ Con la dictación de la Ley № 20.253 de 11/03/2008, se incorpora en forma explícita al artículo 140 del CPP, como causal de justificación cautelar: "el peligro de fuga", como una causal alternativa del "peligro para la seguridad de la sociedad". Como se verá más adelante, la primera causal, era considerada por la doctrina procesal penal nacional como equivalente a la segunda, o en otros términos, los esfuerzos interpretativos consideraban que la única interpretación posible, conforme al texto constitucional y los tratados internacionales sobre derechos fundamentales incorporados al derecho interno, conforme el artículo $5^{\circ}$ inciso $2^{\circ}$ de la CPR, era considerar que la letra c) del artículo 140 del CPP, contenía en la cláusula genérica: "peligro para la seguridad de la sociedad", una causal de riesgo de fuga del imputado, y con ello frustrar los fines del proceso.
} 
legislación viene dada por exigencias que se agrupan, al decir de la doctrina ${ }^{12}$, en un "(...) mosaico y variopinto de presupuestos de difícil reconducción a un denominador común $(. .$.$) ", caracterizado por el "reino de la incertidumbre y$ del arbitrio judicial, que puede llegar a ser «arbitrariedad» apenas limitada por unos presupuestos en los que predomina la apreciación subjetiva del juez que debe tomar la decisión".

Se debe agregar que, además de los presupuestos indicados, la prisión preventiva tiene como límites en cuanto a su procedencia, ciertos principios, los cuales se encuentran explicitados en el CPP, y ellos son: La subsidiariedad, es decir, esta medida sólo puede operar cuando las restantes medidas cautelares personales son insuficientes para lograr los fines procesales y del sistema penal, principio consagrado en los artículos 112 y 139 inciso $2^{\circ}$ del CPP. Además de ello, la prisión preventiva deberá respetar el principio de proporcionalidad, lo cual implica que ella no puede ser más gravosa que la sanción probable; y/o que los costos que implica para el sistema la libertad del imputado, son mayores que el costo que implica su afectación de libertad. La doctrina ve la consagración de dicho principio en los artículos 122, 124; y, 141 del CPP.

Respecto de las causales relativas a la necesidad de cautela, aquella que mayor problema plantea en su interpretación es la cláusula genérica denominada por nuestra legislación: "Peligro para la seguridad de la sociedad". Dicha problemática se acrecienta, luego de las reformas que se han ido introduciendo al $\mathrm{CPP}$, a poco tiempo de su entrada en vigencia. Dentro de estas modificaciones, se encuentra la Ley $N^{\circ} 20.253$ conocida como "agenda corta antidelincuencia", que introdujo diversas modificaciones en materias tales como: Facultades policiales, Flagrancia, Reincidencia, y muy especialmente en la regulación de la prisión preventiva, en donde las modificaciones más sustanciales y polémicas dicen relación con el efecto del recurso de apelación interpuesto por el Ministerio Público en determinados delitos, y la inclusión del peligro de fuga como una causal alternativa del peligro para la seguridad de la sociedad. Lo anterior, acrecienta las dificultades para dilucidar el contenido de la cláusula "peligro para la seguridad de la sociedad", pues al hacer el legislador la distinción entre ésta y el peligro de fuga, podría llevar a pensar que esta polémica cláusula implica necesariamente ser considerada de un modo diferente a la segunda ${ }^{13}$

\footnotetext{
${ }^{12}$ Muñoz CONDE, Francisco, "Cuestiones teóricas y problemas prácticos de la prisión provisional", en Prisión provisional, detención preventiva y derechos fundamentales, Ediciones de la Universidad de Castilla - La Mancha (Estudios; 41), Cuenca - España, 1997, p. 223.

${ }^{13}$ Lama Díaz, Rossy, "Agenda Corta Antidelincuencia. Modificaciones al Código Procesal Penal", en Gaceta Jurídica № 238, 2008, p. 17, para quien "su inclusión como elemento adicional plantea dos cuestiones, la primera de ellas es que se permite decretar la prisión preventiva por la sola existencia de esta circunstancia; y como elemento adicional ésta deberá tener una aplicación restringida, toda vez que nos se establecieron los elementos que lo determinan, como las demás causales; por lo tanto, se deberá aplicar en forma subsidiaria y fundarla según las circunstancias que cada caso lo ameri-
} 
y, por ende, considerar a la primera como un mecanismo dirigido a combatir a los imputados reincidentes, es decir, se estará utilizando la "prisión preventiva" como un medio de control social ${ }^{14}$.

Para efectos del análisis de los casos en comento, creemos necesario hacer una somera descripción del estado de la cuestión, en específico, en lo que comúnmente se ha exigido por presupuesto material, proporcionalidad y peligro para la seguridad de la sociedad, que son aquellos requisitos exigidos por la ley, doctrina y jurisprudencia, como necesarios para decretar esta medida cautelar y que, en la especie, entendemos no han sido respetados por las razones que se indicarán.

\section{Presupuesto material ${ }^{15}$}

Dichos requisitos se encuentran establecidos en el artículo 140 del CPP ${ }^{16}$. Se ha entendido por nuestra doctrina, que para poder decretar la prisión preventiva, en un proceso seguido en contra de una persona que se presume inocente, se requiere que el juez necesariamente haga una ponderación de los antecedentes que presenta el Ministerio Público o el querellante en la audiencia respectiva, y que los mismos lleven al juzgador, mediante un juicio de probabilidad acerca de la participación del imputado y la existencia del delito, a concluir que existe un alto grado de probabilidad de que: 1) El caso será llevado a juicio, o no se le dará termino a través de mecanismos alternativos a él, a excepción de un procedimiento abreviado y 2) Que en ese juicio existirá, conforme a esos antecedentes y los que razonablemente aparezcan durante el curso de la investigación, una gran probabilidad de dictarse una sentencia condenatoria en contra del imputado.

te". Sin embargo, no concordamos con dicha interpretación que da la autora, toda vez que, como se indicará, nuestra doctrina en su mayoría siempre entendió que una interpretación racionalmente posible de la causal de peligro para la seguridad de la sociedad, debía ser el considerar el peligro de fuga del imputado, pues entenderlo de otro modo era incompatible con el texto constitucional. En este contexto, creemos que el intérprete dentro de las tantas opciones que tenga debe conducir su labor por aquella que se ajuste a la Constitución, en ese orden de cosas, puede señalarse que lo que el legislador quiere es reforzar este peligro de fuga, que impediría el cumplimiento de los fines de proceso y del sistema penal.

${ }^{14} \mathrm{Al}$ respecto, pueden consultarse: Horvitz; López, Derecho, cit. nota n. 9. Duce; Riego, Proceso, cit. nota n. 9.

${ }^{15}$ Para un análisis detallado sobre el mismo, puede consultarse DucE; RIEGO, Proceso, cit. nota n. 9, pp. 251 y ss., Horvitz; López, Derecho, cit. nota n. 9, p. 400 y siguientes; y, la obra más actual, que incluye las últimas modificaciones legales: Maturana MiQuel, Cristián; Montero López, Raúl, Derecho Procesal Penal, Tomo I, Editorial AbeledoPerrot LegalPublishing, Santiago, 2010, pp. 491 y ss.

${ }^{16} \mathrm{El}$ artículo 140 del CPP, dispone en sus letras a y b, lo siguiente: a) Que existen antecedentes que justificaren la existencia del delito que se investigare; b) Que existen antecedentes que permitieren presumir fundadamente que el imputado ha tenido participación en el delito como autor, cómplice o encubridor. 


\section{Peligro para la seguridad de la sociedad}

Si bien, no pretendemos en este comentario hacer un análisis profundo de la causal ni desentrañar el contenido de la misma, sí podemos indicar que nuestra doctrina procesal ha hecho importantes esfuerzos por interpretar dicha cláusula. Al respecto, se debe tener presente que, en una materia como ésta, por ser limitativa de derechos y por así disponerlo el artículo $5^{\circ}$ inciso $2^{\circ}$ del CPP, la interpretación de la misma debe ser restrictiva, proscribiéndose la analogía.

El legislador ha entregado algunos criterios respecto de cuándo la libertad del imputado es peligrosa para la seguridad de la sociedad. Así el artículo 140 letra c) del CPP, dispone que: (...) Para estimar si la libertad del imputado resulta o no peligrosa para la seguridad de la sociedad, el tribunal deberá considerar especialmente alguna de las siguientes circunstancias: La gravedad de la pena asignada al delito; el número de delitos que se le imputare y el carácter de los mismos; la existencia de procesos pendientes, y el hecho de haber actuado en grupo o pandilla.

Se entenderá, especialmente, que la libertad del imputado constituye un peligro para la seguridad de la sociedad, cuando los delitos imputados tengan asignada pena de crimen en la ley que los consagra; cuando el imputado hubiere sido condenado con anterioridad por delito al que la ley señale igual o mayor pena, sea que la hubiere cumplido efectivamente o no; cuando se encontrare sujeto a alguna medida cautelar personal, en libertad condicional o gozando de alguno de los beneficios alternativos a la ejecución de las penas privativas o restrictivas de libertad contemplados en la ley (...)".

La doctrina procesal penal nacional que ha interpretado esta causal, lo ha hecho en forma previa a la modificación de la Ley $\mathrm{N}^{\circ}$ 20.253. Sin embargo, conviene traer a colación sus argumentos, pues igualmente orientarán la interpretación de un asunto que no es de fácil despacho.

Si bien Marín González ${ }^{17}$ parte por reconocer la problemática que esta causal conlleva, indica que el legislador en el artículo140 del CPP proporciona ciertos elementos que permiten reconducir la interpretación de dicha norma a los fines cautelares que la doctrina señala debe cumplir esta institución, "lo que busca el legislador al explicitar en este inciso -el tercero- los motivos que especialmente debe tener presente el juez al considerar si la libertad del imputado es peligrosa para la seguridad de la sociedad, no es otro que poner de manifiesto el peligro de que en definitiva el imputado no comparezca al juicio y, en su día, a la aplicación de la eventual pena".

\footnotetext{
${ }^{17}$ Marín González, Juan Carlos, "Las medidas cautelares personales en el nuevo Código Procesal Penal Chileno", Revista de Estudios de la Justicia No 1, 2002. En: http://web.derecho.uchile.cl/cej/ recej/recej1/ archivos/Medidas_Cautelares_personales\%20(5).pdf [visitado el 21/09/2010].
} 
Por su parte, Horvitz y López ${ }^{18}$ plantean que, si bien existen interesantes esfuerzos en ver en la causal en comento, un símil del peligro de fuga-citan en su obra él ya aludido artículo de Marín ${ }^{19}$ - dicha argumentación no les convence, dada la fuerza cultural que en nuestro sistema tiene esta causal cautelar. Por ello, para estos autores, la causal no es más que un "peligro de reincidencia", lo que puede observarse cuando el legislador alude a consideraciones como: la existencia de procesos pendientes, el hecho de encontrarse sujeto a alguna medida cautelar personal, en libertad condicional o gozando de algunos de los beneficios alternativos a la ejecución de las penas privativas o restrictivas de libertad, la existencia de condenas anteriores cuyo cumplimiento se encontrare pendiente, entre otros. En definitiva, en concepto de estos autores, a través de dicha cláusula se estarán legitimando fines de prevención especial negativos, o mecanismos de control social, cuya ilegitimidad es patente y, por lo mismo, comprometería el incumplimiento de las obligaciones del Estado de Chile contraídas en los documentos internacionales que han sido suscritos sobre la materia ${ }^{20}$.

Finalmente, para Duce y Riego ${ }^{21}$, la ambigüedad que ha existido sobre lo que implica el peligro para la seguridad de la sociedad, es algo que se traspasó de la antigua legislación ${ }^{22}$ al CPP. Así, para estos autores, los criterios informativos que el artículo 140 letra c) señala, no serían más que criterios destinados a ser ponderados por el arbitrio judicial. De este modo, el peligro para la seguridad de la sociedad incluiría, según Duce y Riego, el peligro de fuga, la reiteración delictiva y la alarma pública o legitimidad del sistema. Lo primero y segundo, lo deducen de las consideraciones que la ley indica en el artículo 140 del CPP,

\footnotetext{
${ }^{18}$ Horvitz; LÓPEZ, Derecho, cit. nota n. 9, pp. 415- 416. Así indican que: “El peligro para la seguridad de la sociedad es, sin lugar a dudas, la justificación más problemática para la prisión preventiva, porque resulta evidente que, en este caso, deja de ser una medida cautelar para convertirse en un instrumento de control social, lo que claramente pone en crisis su legitimidad".

${ }^{19}$ Horvitz; López, Derecho, cit. nota n. 9, pp. 415- 416, "El mérito de este argumento es indudable, en cuanto pretende solucionar, por vía interpretativa, una seria inconsistencia de nuestro ordenamiento jurídico que, entendido de otro modo, autoriza la privación de libertad sobre la base de criterios de defensa social que nos parecen inaceptables. Sin embargo, se trata de un esfuerzo interpretativo que no resulta convincente, porque no logra desvirtuar toda la fuerza que, en nuestra cultura jurídica, tiene la noción de 'peligro para la seguridad de la sociedad', como equivalente de 'peligro de reincidencia'.

${ }^{20}$ El artículo 9.3 del Pacto Internacional de los Derechos Civiles y Políticos, por su parte, sólo permite subordinar la libertad a "garantías que aseguren la comparecencia del acusado en el acto del juicio, o en cualquier otro momento de las diligencias procesales y, en su caso, para la ejecución del fallo". Por su parte, la Convención Americana de Derechos Humanos, en su artículo 7.5 sólo autoriza a condicionar la libertad del imputado "a garantías que aseguren su comparecencia en el juicio".

21 Duck; Riego, Proceso, cit. nota n. 9, pp. 260 y ss.

${ }^{22}$ Nos referimos a la regulación que existía en el antiguo 363 del Código de Procedimiento Penal de 1906, y que sufrió modificaciones mediante las Leyes Nos. 19.503 de 1997 y 19.661 de 2000. 
y para el tercer supuesto de peligro para la seguridad de la sociedad, lo extraen que una negación de la misma puede provocar una grave afectación de la legitimidad del sistema, lo que podría originar una alarma social o deteriorar la seguridad que el mismo sistema debe brindar a la población. Ciertamente, que estos postulados son de compleja justificación, y muy cuestionables desde el punto de vista constitucional, en un Estado respetuoso de los derechos humanos y de la dignidad humana, pero con una visión bastante realista del modo como esta medida cautelar es utilizada en la práctica.

En consecuencia, y tal como lo indicábamos en un comienzo, nos encontramos ante causales bastante indeterminadas, lo que, en palabras de Muñoz Conde $^{23}$, deja abierta la puerta a lo incierto, transformando el arbitrio del juzgador en algo arbitrario, legitimándose mediante esta cláusula verdaderos mecanismos de control social.

Pero no debemos perder de vista que, en la práctica, más allá del marco teórico y conceptual que hemos desarrollado, la aplicación de la prisión preventiva es utilizada político criminalmente en la lucha contra un determinado grupo de imputados: 1) Los reincidentes, 2) Los delitos contra la propiedad, esencialmente el robo en cualquiera de sus formas y 3) La violencia intrafamiliar, en casos de supuesta reiteración. Esto es cuestionable, ciertamente, en tanto implica considerar que la prisión preventiva deja de ser una medida cautelar que tenga por objeto el cumplimiento de los fines del proceso, lo cual sería más bien una función de la pena y, por otro lado, al asignarle a la prisión preventiva fines preventivos especiales, se vulneraría el principio de inocencia, pues se estaría imponiendo una pena, no obstante, no ha existido juicio alguno en contra del imputado, infringiéndose con ello garantías constitucionales. Pero, reiteramos, que dichos fundamentos sin ser explícitamente señalados, son reiteradamente ocupados en el día a día, y es lo que se indica como fundamentos apócrifos de la prisión preventiva. Ratifica dicha situación, que el año 2006 fueron sometidos a prisión preventiva en nuestro país 14.348 imputados, tres años más tarde, esta cifra aumentó a 19.979 personas ${ }^{24}$.

Estas críticas son actualmente objeto de análisis, haciéndose esfuerzos por superar las inconsistencias que presentaría la fundamentación cautelar de la prisión preventiva. En este sentido, autores como Ragués ${ }^{25}$ consideran que la

\footnotetext{
${ }^{23}$ Cit. nota n. 12.

${ }^{24}$ MEMORIA ANUAL DE LA DEFENSORÍA PENAL PÚBLICA DE CHILE, 2009, p. 61.

${ }^{25}$ Véase en: Ragués I Valles, Ramón, "Derecho Penal Sustantivo y Derecho Penal: Hacia una visión integrada", Anuario de Derecho Penal, Perú, 2004, pp. 129-163, y "Prisión Provisional y Prevención de Delitos ¿Legítima protección de bienes jurídicos o derecho penal del enemigo?", en Cancio MeliA, Manuel; Gómez-Jara Diez, Carlos (Coords.), Derecho Penal del Enemigo. El discurso penal de la exclusión, Editorial B de F, Buenos Aires-Argentina, 2006, pp. 713 - 734.
} 
tradicional separación que ha existido entre el Derecho Penal y Procesal Penal, ha provocado que distintas instituciones como la prueba, la prescripción y la prisión preventiva sean analizadas exclusivamente desde un prisma procesal. En ese contexto, considera que "el proceso penal no es un fin en sí mismo susceptible de legitimación, sino sólo el cauce previsto para que pueda imponerse la pena y ésta despliegue sus efectos preventivos. En otra palabras: la frustración en un caso concreto del fin del proceso no es algo negativo per se, sino sólo en la medida en que dicha frustración impide que la pena pueda desplegar sus efectos preventivos y contribuir al fin último de pacificación social que pretende la globalidad del sistema" ${ }^{26}$. En ese contexto, postula que la prisión preventiva evita que puedan frustrarse los fines de la pena, contribuyendo con ello a la función pacificadora del Derecho Penal, siempre que la misma -prisión preventiva- cumpla los presupuestos de: proporcionalidad, subsidiariedad y probabilidad ${ }^{27}$. Así, concluye que la prisión preventiva sólo será legítima como medio en la prevención de delitos, en aquellos casos en los que, si el imputado permaneciera en libertad, existiría un riesgo grave y concreto de la alteración de la paz social o de lesión o puesta en peligro grave de los bienes jurídicos más importantes, sin que para conjurar dicho peligro, exista ningún medio menos lesivo que la privación de libertad del imputado.

\section{Proporcionalidad}

Como se indicó anteriormente, este principio se encuentra contemplado en los artículos 122, 139 inciso $2^{\circ}$, y en el artículo 141 del Código Procesal Penal. La doctrina procesal penal indica que el principio de proporcionalidad, en las medidas cautelares personales que se adopten en el curso de un proceso penal, han de estar en relación con la finalidad del procedimiento que se persigue cautelar y con la gravedad del hecho que se investiga ${ }^{28}$. Ahora bien, la proporcionalidad en la prisión preventiva guarda directa relación con otros principios limitadores de esta medida, como es su instrumentalidad (idoneidad como proporcionalidad en sentido amplio), es decir, ellas son impuestas para que el proceso logre sus fines (artículo 122 inciso $2^{\circ}$ ). Así se indica que una interpretación en contrario, implicaría poner los medios por sobre los fines ${ }^{29}$.

\footnotetext{
${ }^{26}$ RAGUÉS, "Prisión", cit. nota n. 25, p. 716.

${ }^{27}$ RAGUÉS, "Derecho", cit. nota n. 25, este autor plantea que: para legitimar la prisión preventiva como un instrumento que posibilite el cumplimiento de los fines de la pena, no frustrando los mismos, o afectándolos negativamente, los antecedentes que fundamentan la existencia del hecho y la participación del imputado, deben llevar a una alta probabilidad de que en un juicio el imputado será condenado, a fin de evitar encarcelamientos injustificados.

${ }^{28}$ Horvitz; López, Derecho, cit. nota n. 9, p. 353.

${ }^{29}$ Duce; RieGo, Proceso, cit. nota n. 9, p. 266.
} 
Por otro lado, también se vincula a este principio con la subsidiariedad de las medidas cautelares, es decir, sólo se justifica una privación de libertad en el proceso, si no existen otras medidas menos gravosas que permitan cumplir con las finalidades del proceso (necesariedad como componente de la proporcionalidad), lo que se consagra en el artículo 139 inciso $2^{\circ}$ del CPP. Finalmente, también se le vincula con el principio de la temporalidad de las mismas, lo que implica que la prisión preventiva sólo durará mientras subsistan los presupuestos que la hacían procedente, tal como se indica en el artículo 152 del CPP (proporcionalidad en sentido estricto). Determinada la idoneidad, necesidad y ponderación de las circunstancias que concurran en la especie, podemos realizar el juicio de proporcionalidad en sentido estricto de la prisión preventiva. Así, ésta será proporcional cuando "el sacrificio de los intereses individuales que comporta la injerencia, guarda una relación razonable o proporcionada con la importancia del interés estatal que se trata de salvaguardar ${ }^{30 \prime}$. En consecuencia, "si el sacrificio resulta excesivo, la medida deberá considerarse inadmisible, aunque satisfaga el resto de presupuestos y requisitos derivados del principio de proporcionalidad"31.

\section{Consideraciones sobre las Sentencias en COMEnto}

a) Tanto en la resolución de la Ilustrísima Corte de Apelaciones de Concepción, que conoció las acciones constitucionales de amparo en contra de las resoluciones de los Juzgados de Garantía de Concepción, como las resoluciones de la Excelentísima Corte Suprema, que conocieron de las apelaciones de las acciones de amparo, se aprecia una ausencia de fundamentación. Lo anterior, creemos que es una deficiencia de las resoluciones que comentamos, pues se trata de resoluciones que recaen en asuntos sobre derechos y garantías fundamentales. Así, por lo demás, el artículo 36 del CPP establece el deber de fundamentar toda resolución judicial, norma que se ve reafirmada por lo que dispone el artículo 143 del mismo Código, que es aplicable en específico a la prisión preventiva. Podría observarse que la resolución del Juzgado de Garantía que decretó la medida cautelar, fue debidamente motivada. Sin embargo, somos de opinión que, dada la trascendencia de los mismos -se trataba de casos ocurridos en una situación de emergencia constitucional, producida por un desastre natural-, la exigencia para resolver y mantener la privación de libertad por razones de interés público o como se indica: "peligro para la seguridad de la sociedad", debe ser suficientemente fundada, lo que no ocurrió en la especie.

${ }^{30}$ González-Cuéllar Serrano, Nicolás, Proporcionalidad y Derechos Fundamentales en el Derecho Penal, Editorial COLEX, Madrid, España, 1990, p. 225.

${ }^{31}$ González-Cuéllar, Proporcionalidad, cit. nota n. 30, p. 225. 
Esta será la única forma de evitar la arbitrariedad y posibilitar al mismo tiempo el control ${ }^{32}$. Así, Ragués ${ }^{33}$ es de la opinión que una prisión preventiva que pudiera ser considerada legítima por su contribución directa al aseguramiento de la paz social, exigiría mucho más que la constatación de un riesgo abstracto de perturbación del orden, siendo necesario que dicho riesgo fuera apreciado por el juez de forma motivada en el momento de adoptar la medida sobre la base de antecedentes inequívocos. En la especie, podemos apreciar que los fallos se limitan a reproducir las resoluciones recurridas mediante la cláusula "vistos se confirma", y en el caso de las resoluciones de Cortes de Apelaciones, éstas se limitan a la reproducción de lo argumentado por los recurrentes y las resoluciones recurridas, para en dos breves considerandos, desechar las acciones constitucionales. Todo lo anterior, no es nada más contrario a lo que se espera de las actuaciones de los órganos jurisdiccionales en un Estado Democrático de Derecho, conforme a los artículos $1^{\circ}, 4^{\circ}$ y $5^{\circ}$ inciso $2^{\circ}$ de la $\mathrm{CPR}^{34}$. De este modo, las resoluciones de los Tribunales de Garantía, que privaron de libertad a personas sin antecedentes penales y por delitos de baja penalidad, haciendo alusión en su fundamentación a la calamidad pública producida por el terremoto, y los posteriores ataques a la propiedad privada, denominados saqueos, sin hacer referencia a cómo la libertad del imputado afectaría el orden público, o cómo la privación de libertad contribuiría al restablecimiento del mismo, ya sea en razón del peligro de reiteración criminal o, simplemente, por razones del peligro que la libertad del imputado puede generar graves reacciones de la comunidad y, con ello, la deslegitimación del sistema criminal. Por ello, la simple utilización o alusión de frases sacramentales, resultan insuficientes para justificar una privación de libertad.

En sentido, es un lugar común el planteamiento de que reunidos los supuestos señalados en el artículo 140 del CPP relativos a "peligro para la seguridad de la sociedad", se debe casi automáticamente decretar la prisión preventiva. Nada de ello puede ser más contrario al tenor de la ley y la Constitución, en tanto y en cuanto es el juez quien debe ponderar dichas circunstancias, éstas y los antecedentes del caso concreto determinarán según su razonar si la prisión preventiva es o no aplicable. Así nuestra Excelentísima Corte Suprema, lo ha

32 González-Cuéllar, Proporcionalidad, cit. nota n. 30, pp. 141 y ss.

33 RaGués, "Prisión", cit. nota n. 25, p. 726.

${ }^{34}$ En este sentido el Tribunal Europeo de Derechos Humanos en el caso "Letelier", sentencia del año 1991, señaló que la prisión preventiva puede estar legitimada por ciertos motivos de orden público, pero dichos motivos deben estar suficientemente motivados, y así también, el tribunal exige, como es obvio, que para acordar la prisión por este motivo existan datos capaces de acreditar la existencia del tal riesgo. Citado por Ragués, "Derecho", cit. nota n. 25, p. 157. 
reiterado en números fallos ${ }^{35}$. Ello implica que la resolución que decrete estas medidas debe ser fundada, y no puede simplemente repetir estas causales, pues aquello incumple los artículos 36 y 143 del CPP. En la especie, como decíamos, y por haberse decretado esta medida en una situación excepcional y por fundamentos cuestionables, como es la alarma social, originada por la calamidad pública producida por el terremoto del 27 de febrero de 2010, la fundamentación debió ser mucho más detallada, y no simplemente hacer alusiones genéricas, pues es aquello, precisamente, lo que la doctrina denuncia como el paso de la razonabilidad judicial a lo irrazonable ${ }^{36}$.

b) Como se indicó, las citadas resoluciones omiten fundamentar lo resuelto y, por lo mismo, reproducen las resoluciones recurridas de amparo, lo que resulta criticable bajo todo punto de vista. Ahora bien, si se consideran como fundamentos aquellos esgrimidos por los respectivos jueces de garantía recurridos, nos percatamos que como es tradicional, estas resoluciones se centran básicamente en fundar la prisión preventiva, haciendo referencia casi en su totalidad a la necesidad de cautela. Ello, como se dijo en el punto anterior, mediante la utilización de supuestos generales y abstractos indicados en el artículo 140 del CPP, y además en estos casos, en la situación de excepción. Esto, nos lleva a concluir que los requisitos materiales, como existencia del ilícito y participación, como es costumbre ${ }^{37}$ no son analizados con la rigurosidad que la materia amerita, lo cual es inconsistente con la afectación de derechos y garantías, que la resolución que se dicta importa.

De este modo, resulta curioso como en uno de los casos en análisis, los hechos formalizados consistirían en que el imputado tendría en su poder una lavadora que provendría de unas bodegas comerciales del sector Palomares de Concepción, no indicándose en la comunicación fáctica a quién, previamente, pertenecía dicho artefacto, ni menos se invoca si la receptación provendría de otros delitos contra la propiedad, o de otra receptación, conforme el tipo del artículo 456 bis A del CP. Se indica simplemente que dicha especie habría sido "sustraída". Es decir, la propia formalización de cargos no contendría todos los supuestos fácticos que el tipo exige. Esto tiene relevancia, pues de acuerdo

\footnotetext{
${ }^{35}$ Sentencias de la Excelentísima Corte Suprema: 1) Aquella que acoge recursos de apelación en contra de la resolución de la Ilustrísima Corte de Apelaciones de San Miguel, que rechazó la acción de amparo constitucional, 13 de enero de 2009, rol 192-2009,2) Aquella que acoge recursos de apelación en contra de la resolución de la llustrísima Corte de Apelaciones de San Miguel, que rechazó la acción de amparo constitucional, 15 de julio de 2009, rol 4823-2009 y 3) Aquella que acoge recursos de apelación, en contra de la resolución de la llustrísima Corte de Apelaciones de Santiago, que rechazó la acción de amparo constitucional, 20 de julio de 2009, rol 4922-2009.

${ }^{36}$ MuÑoz, "Cuestiones", cit. nota n. 9.

${ }^{37} \mathrm{Al}$ respecto, RaGués, "Derecho", cit. nota n. 25.
} 
con lo dispuesto en el artículo 259 del CPP, la acusación debe referirse a los mismos hechos que los contenidos en la formalización. Ahora bien, creemos que dicha situación, y que se refiere a la descripción de la conducta que debe encuadrarse en el tipo del artículo 456 bis A del CP, incide en los presupuestos de las letras a y b del artículo 140 del CPP, pues el tipo penal exige que las especies hubieren sido hurtadas, o robadas, o producto de otra receptación, ello como mínimo para establecer que la conducta típica imputada es constitutiva del delito imputado u otro. En la especie, la formalización no cumple las exigencias del tipo penal de receptación y, en consecuencia, no se podría haber tenido por acreditado el presupuesto material, toda vez que ni siquiera la imputación cumplía las exigencias del tipo por el que se formalizó investigación.

Lo denunciado, en ningún caso puede ser considerado irrelevante, puesto que los mismos hechos que fueron comunicados a los amparados deberán posteriormente ser objeto de acusación, y luego sentencia, acorde lo indica el artículo 341 del CPP. La falta de dicha congruencia, acarrea la nulidad del juicio oral y la sentencia de acuerdo con el artículo 374 letra e) del CPP. Por otro lado, cabe tener presente que la Ilustrísima Corte de Concepción, conociendo recursos de nulidad en causas en juicios simplificados por delitos de receptación, entiende que: si los hechos probados se limitan a indicar que las especies han sido sustraídas, dichos hechos no son constitutivos del delito de receptación del artículo 456 bis A del $\mathrm{CP}^{38}$. Dicha situación, ni siquiera aparece enunciada en ninguno de los fallos en análisis.

Aunque no compartimos del todo que la prisión preventiva pueda ser esgrimida para fines preventivos generales, la doctrina entiende que "asumiendo tal función, puede conseguirse una importante restricción de su empleo, exigiendo que para su aplicación no baste con la mera constatación de la concurrencia de meras sospechas o indicios de criminalidad, sino la necesidad de que consten en lo instruido elementos indiciarios que, por su número e importancia, permitan afirmar con un escaso margen de error que, en el caso de hacerse valer en el acto del juicio por la acusación, permitirán considerar probada la culpabilidad del imputado $39 "$. De este modo, a las resoluciones en análisis, y por las especiales circunstancias del caso, les era exigible una mayor motivación del presupuesto material, dado que lo que se intentaba comunicar mediante ellas, era que la privación de libertad de los imputados era algo necesario, debido a la alarma

\footnotetext{
${ }^{38}$ Sentencia de la Iltma. Corte de Apelaciones de Concepción, acoge recurso de nulidad en contra de la sentencia del Tribunal de Garantía de Cañete, presentado por la defensa, 25 de mayo 2010, Rol 155-2010.

${ }^{39}$ Ragués, "Derecho", cit. nota n. 25, p. 159.
} 
social originada por los saqueos en los cuales, supuestamente, ellos habían participado, guardando las especies provenientes de los mismos. Por tal motivo, y si se estima que la prisión preventiva puede operar con fines preventivos generales (negativos o positivos), lo cual como decíamos es discutible ${ }^{40}$, debe exigirse una motivación suficiente del presupuesto material. Entender lo contrario, implica y provoca un uso masivo del encarcelamiento preventivo con lo cual se vulneraría la garantía jurisdiccional de la pena. Como se dijo, nada de esto ocurrió en la especie, ni con el presupuesto material, ni con la necesidad cautelar de peligro para la seguridad de la sociedad. Lo anterior, creemos que lamentablemente ocurrió con la utilización masiva que se hizo de esta medida cautelar en los hechos vinculados al 27 de febrero. Así, más de 300 personas fueron detenidas y encarceladas preventivamente en la Región del Bío-BíO' ${ }^{41}$, todas ellas, o en su mayoría, con el único fundamento de privarlas de su libertad por la "alarma social" que su libertad, supuestamente, contribuía a aumentar, y con presupuestos materiales muy precarios. Sin embargo, esta práctica parece no ser sólo aplicable en tiempos de excepción, pues según cifras de la Defensoría Penal Pública, existe un creciente número de personas de son privadas de libertad y luego absueltas. Así, según su Memoria Anual $2009^{42}$, un $22,1 \%$ de los imputados absueltos fueron privados de libertad. Seguramente en muchos de esos casos, las resoluciones que privaron de libertad a los imputados no tuvieron un adecuado fundamento del presupuesto material ${ }^{43}$.

c) Si bien la prisión preventiva es una medida cautelar, no podemos negarnos a la realidad que implica que es un instrumento, a través del cual el sistema penal cumple su función más importante, como es la aplicación y ejecución de la pena y sus efectos ${ }^{44}$. Por ello, no podemos dejar de analizar la prisión preventiva como un instrumento que garantiza que la pena despliegue todas

\footnotetext{
${ }^{40}$ Asencio Mellado, José María, La Prisión Provisional. Tesis Doctoral de la Universidad de Alicante, España, 1987, p. 27. En: http://rua.ua.es/dspace/handle/10045/3483 [visitado el 29/09/2010].

${ }^{41}$ Cifra entregada por OIRS Defensoría Regional del Bío-Bío, cit. n. 4.

${ }^{42}$ Cit. nota n. 24.

${ }^{43}$ Un caso paradigmático para el sistema de justicia nacional, lo constituye en esta materia el Ilamado "Caso del Violador de Nuñoa", quien fuera detenido y sometido a prisión preventiva por la llustrísima Corte de Apelaciones de San Miguel, pese a que el Octavo Juzgado de Garantía de Santiago decretara su libertad, por cuanto los antecedentes del proceso no eran suficientes para acreditar su participación. Días más tarde, el propio Ministerio Público aceptaría la revocación de la medida, puesto que la prueba científica (ADN) ratificaba su inocencia.

${ }^{44}$ Sobre la materia, como se ha indicado, ver RaGués, en los artículos ya citados: "Prisión" y "Derecho", cit. nota n. 25.
} 
sus consecuencias, ello no obstante, estar convencidos del carácter cautelar y procesal de la medida.

Ahora bien, queda meridianamente claro que en los casos en comento, la naturaleza cautelar de la prisión preventiva no fue su sustento. Por lo mismo, podríamos buscar su fundamentación, vinculándola con los fines de la pena, conforme a una de las opciones que hemos revisado anteriormente. Sin embargo, creemos que ninguno de los aquellos fines -de la pena- podría haber permitido que la prisión preventiva hubiere sido aplicada. Así, creemos que aunque cabe descartar de antemano que ella hubiere sido aplicada para fines preventivos especiales positivos, puesto que como indica Ragués ${ }^{45}$, parece poco probable que se pueda considerar necesario privar de libertad a un sujeto para evitar frustrar la eficacia de la pena, por un retraso en la resocialización (por la demora de la práctica del juicio); en el evento que ello no fuera así, como se indicaba más arriba, se trataba de imputados sin antecedentes penales, con actividad laboral actual al momento de los hechos y con arraigo social. En ese contexto, la prisión preventiva no puede ser el instrumento que permita que el sistema penal cumpla sus funciones resocializadoras, ante la falta de agilidad en la aplicación de la pena derivada de la demora en la realización del juicio. Tampoco podríamos señalar que la prisión preventiva, en este caso, sirve de instrumento para evitar una probable afectación de bienes jurídicos, pues, dadas la características de los hechos y de los amparados, no existía riesgo de reiteración. En este sentido, la doctrina ${ }^{46}$ manifiesta que la prisión preventiva sólo podría justificar estos fines cuando, además de existir un riesgo de reincidencia, exista un peligro de afectación para bienes jurídicos de tal entidad, que hagan que el costo de privar a una persona de su libertad sea inferior a la lesión o ataque de bienes de tal envergadura, como puedan ser la vida, la integridad de la persona o su seguridad la libertad sexual, entre otros. O en el caso de bienes jurídicos supraindividuales, cuando a través de dicha afectación se afecte de modo indirecto tales bienes -vida, salud, libertad sexual, seguridad y libertad individual- como son los atentados contra el medio ambiente o la salud pública. Por el contrario, una justificación en esa línea, es decir, que hubiera existido tal peligro de reiteración de conductas atentatorias contra la propiedad o que fomenten tales conductas-receptación, por ejemplo-, debe igualmente ser rechazada, por cuanto colisiona con la necesariedad de la prisión preventiva, como componente de la proporcionalidad en sentido amplio, pues, sí existían otras medidas menos restrictivas de derecho que posibilitaban dichos fines, y que iban desde aplicar alguna de las

${ }^{45}$ Ragués, "Prisión", cit. nota n. 25, p. 723.

${ }^{46}$ RaGués, "Prisión", cit. nota n. 25, p. 724. 
que contiene el catálogo del artículo 155 del CPP, hasta la responsabilidad de los agentes del Estado en haber decretado en tiempo oportuno el estado de excepción constitucional, y haberlo hecho efectivo en toda su magnitud, es decir, mediante una prevención previa, a través de la presencia en terreno de los efectivos militares y policiales. Dicha ausencia, impide legitimar una medida como ésta.

Finalmente, si la prisión preventiva hubiera sido en esos casos considerada como instrumento para evitar, no sólo la frustración de la pena, sino que además para negar toda finalidad preventiva general de la misma, dicha fundamentación tampoco creemos que en el caso en concreto pueda legitimar su aplicación en las situaciones de los fallos que hemos venido comentando. Así, la prisión preventiva, en estos casos, no podía ser un instrumento para fines preventivos generales positivos ni negativos, pues resulta imposible determinar en qué medida dichas privaciones de libertad -que se produjeron a semanas de la catástrofe natural del 27 de febrero- podrían haber incidido en la intimidación de potenciales delincuentes (prevención general negativa), o en la confianza de los ciudadanos en la fidelidad al derecho (prevención general positiva). A mayor abundamiento, debemos considerar que, comportamientos como los enjuiciados, es decir, acopio de especies luego de una catástrofe natural, o evento revolucionario, son conductas que a pesar de la aplicación del sistema penal -la pena- son reiterativas en el tiempo. Así, en nuestra historia, ya en la revolución de 1891 y en el terremoto de Valparaíso de $1906^{47}$ se registraron hechos como los ocurridos luego del 27 de febrero de este año, pese a que tanto en la guerra civil como luego en el puerto, los autores de aquellos hechos fueron sancionados severamente, no obstante, esas sanciones y estas conductas se repiten en el tiempo. Ello no es más que una consecuencia de factores socio-estructurales, psicológicos y del actuar colectivo en situaciones de catástrofe, en donde las personas actúan pensando en el "aquí", tiempo presente, olvidando lo pasado y lo futuro, dando rienda suelta a sus impulsos ${ }^{48}$, y en donde se "despiertan y

\footnotetext{
${ }_{47}$ Brevemente sobre sucesos como los ocurridos en forma posterior al 27 de febrero, pueden verse En: http://latercera.com/contenido/1453_230311_9.shtml [visitado el 17/10/2010]. Aquí se relata la participación del Almirante Luis Gómez Carreño, como el encargado de restaurar el orden en la ciudad de Valparaíso luego del terremoto de 1906, suceso que provocó saqueos y disturbios en la ciudad. Al respecto, cuenta la historia que algunos autores de tales actos fueron fusilados en el lugar por orden de la autoridad de la Armada.

${ }^{48}$ Sobre el particular, ver Green, "Looting", cit. nota n. 1. Allí se hace un análisis histórico de las situaciones que configuran lo que se califica como saqueo, y se ejemplifica con lo sucedido luego del huracán Katrina, donde luego de la catástrofe las personas dieron rienda suelta a su desesperación, haciéndose fácil presa de los medios de comunicación que informaban y juzgaban lo ocurrido, calificándolos de buenos y malos saqueadores. Los primeros, aquellos que acumulaban y recogían especies para su alimentación (generalmente de raza blanca), y los segundos, los que acopiaban y sacaban de
} 
posicionan necesidades a resolverse individual o colectivamente, a raíz de la ineficiencia de las autoridades" ${ }^{\prime \prime 9}$ En consecuencia, y dado que sucesos como los ocurridos el 27 de febrero de 2010, son eventos que gatillan conductas en las personas que difícilmente pueden ser reconducidas a un respeto siempre irrestricto a las normas, dados los factores que hemos indicado, podemos concluir que la prisión preventiva, incluso para efectos preventivos generales no cumple finalidad alguna, pues no existirá intimidación penal que pueda garantizar, que en 25 años más, de repetirse en Chile un evento como éste-lo que es altamente probable, dada nuestra estadística histórica en la materia-, no vuelvan a ocurrir eventos como los que hemos comentado.

En consecuencia, en estos casos la prisión preventiva está motivada por fines claramente simbólicos, es decir, se trató de una intervención penal no suficientemente legítima, que no se acomoda al fin político criminal que funda la pena y, por lo mismo, el sistema penal ${ }^{50}$. La argumentación dada por las resoluciones objeto de comentario, es decir, que la libertad de los imputados constituía un peligro para la sociedad, son motivos que no satisfacen un juicio de proporcionalidad.

e) Finalmente, consideramos que en ambos casos la prisión preventiva no sólo resultaba desproporcionada, por no ser idónea ni necesaria, sino que también por ser desproporcionada con la sanción probable. En la especie, en ambos casos se trata de situaciones en que los imputados cumplirán sus penas en libertad, gozando de los beneficios de la Ley № 18.216 sobre formas alternativas al cumplimiento de penas privativas de libertad. Es más, en ambos casos, sus causas han terminado con penas cuyo cumplimiento no es privativo de libertad. Así, en uno de los casos, causa RUC 1010006270-K, la pena fue de 41 días de prisión en su grado medio, más la pena pecuniaria de 2 unidades tributarias mensuales. Dicha sentencia fue recurrida por la defensa del imputado, fallo que se encuentra pendiente a esta fecha, y que será objeto de nuevo comentario.

En conclusión, las resoluciones que se comentan no cumplieron las exigencias de una adecuada fundamentación, ni legitimación de la medida de privación de derechos que estaban decretando, exigencias que en una situación

\footnotetext{
todo (generalmente de raza afroamericana). En uno y en otro caso, este autor indica que se trata de situaciones límite en donde las personas no actúan pensando en lo que sucederá ni en los sucedido, sino cómo y qué me puede ayudar a subsistir, lo que puede ser alimento, o también especies que pueda luego reducir o cambiar.

${ }^{49}$ Matus Acuña, Alejandra, "Nuestro Huracán Katrina", Diario Electrónico El Mostrador, 1 de marzo de 2010. En: http://www.elmostrador.cl/opinion/2010/03/01/nuestro-huracan-katrina/ [visitado el 17/10/2010].

${ }^{50}$ Díez Ripoltés, José Luis, "El Derecho Penal Simbólico y los Efectos de la Pena", en Crítica y Justificación del Derecho Penal en el cambio de siglo, Ediciones Universidad Castilla - La Mancha (Estudios; 91), Cuenca 2003, pp. 147-172.
} 
de excepción son aún más exigibles, toda vez que la Constitución mantiene el control del apego a la juridicidad en manos de los órganos judiciales. Por ello, como indicaron al poco tiempo de sucedido el terremoto y maremoto, Hernández y Couso ${ }^{51}$ : "las medidas excepcionales adoptadas en ese marco siguen sometidas al derecho, uno que en nuestros días no se entiende sin referencia a los derechos humanos (...) y que consecuentemente sólo legitima el ejercicio de la fuerza estricta y racionalmente necesaria para la mantención del orden, sin espacio para alardes ejemplificadores", como al parecer, fue lo que sucedió en la especie.

\footnotetext{
${ }^{51}$ Hernández, Héctor; Couso, Jaime, "Derecho y los Tiempos de Excepción", Diario la Tercera, Ideas y Debates, 4 de marzo de 2010, Santiago de Chile, p. 4.
} 
